\title{
Vitamin E Supplementation Strategies for Newly Received Feedlot Cattle
}

\section{DOI:10.31274/air.12243}

Erin L. Deters, Post-Doctoral Research Associate; Stephanie L. Hansen, Professor, Department of Animal Science, Iowa State University

\section{Summary and Implications}

Increasing doses $(0,150,500$, or $1,000 \mathrm{IU} / \mathrm{d})$ of supplemental vitamin E (VE) fed to newly received steers linearly increased VE status and $150 \mathrm{IU} /$ steer/d was adequate to prevent a decline in VE status over the 26-d trial. Although feedlot performance was not affected by supplemental VE treatments, the highest VE dose $(1,000$ $\mathrm{IU} / \mathrm{d})$ resulted in greater Bovine Viral Diarrhea Virus antibody titers $20 \mathrm{~d}$ after receiving a booster vaccine. The positive effects of VE on antibody titers in the current study, suggest supplemental VE is an effective nutritional strategy for supporting immune system function. Further research is needed to determine the optimal dose and timing of VE supplementation for newly received cattle with specific emphasis on resiliency to, and recovery from, stressful events.

\section{Introduction}

Vitamin $\mathrm{E}$ is a fat-soluble vitamin required for beef cattle, but VE requirements are not well established. The committee on nutrient requirements of beef cattle recommends 11 to $16 \mathrm{IU} / \mathrm{lb} \mathrm{DM}(0.24$ to $0.33 \mathrm{IU} / \mathrm{lb} \mathrm{BW})$ for non-stressed feedlot cattle while a greater dose (400 to $500 \mathrm{IU} / \mathrm{d} ; 0.73$ to $0.91 \mathrm{IU} / \mathrm{lb} \mathrm{BW}$ ) is recommended for newly received, stressed cattle. This recommendation is based on previous research indicating VE doses greater than 400 IU/animal daily may increase ADG and decrease respiratory illness in newly received cattle. Additionally, stressors encountered during the feedlot receiving period, such as transit, decrease VE status. The current study sought to determine the effect of various VE doses, likely representing the majority of supplementation strategies used in feedlot receiving diets, on feedlot performance, $\mathrm{VE}$ status, and vaccination response of newly received beef steers.

\section{Materials and Methods}

This study utilized 204 high percentage Angus steers ( $548 \pm 50 \mathrm{lb} ; 6.5 \pm 0.5 \mathrm{mo}$ of age) from a singlesource in north central NE. On d 0 ( $7 \mathrm{~d}$ after arrival), steers were blocked by weaning protocol and initial BW (pre-weaned [35 d prior to arrival] $=503 \mathrm{lb}$; bawling heavy $=601 \mathrm{lb}$; bawling light $=533 \mathrm{lb}$ ) into partially covered concrete pens ( 5 or 6 steers/pen). Pens within block were randomly assigned to 1 of 4 dietary treatments ( $\mathrm{n}=8$ or 9 pens/treatment): no supplemental VE (CON), supplemental VE as recommended for non-stressed cattle (11 IU/lb DM; LOW), supplemental VE as recommended for stressed cattle (500 IU/steer/d; MED) or supplemental $\mathrm{VE}$ at a pharmacological dose (1,000 IU/steer/d; HIGH). Supplemental VE (ROVIMIX® E-50 Adsorbate, DSM Nutritional Products) was delivered as part of the total mixed ration (Table 1) and VE premix inclusions were adjusted weekly to maintain target VE intakes; back calculated VE intakes for each treatment are shown in Table 2. On a BW basis, back-calculated supplemental VE intake was $0,0.55,1.79$, and $3.67 \mathrm{IU} / \mathrm{kg} \mathrm{BW}$ for CON, LOW, MED, and HIGH, respectively.

Steers were weighed on two consecutive days at the beginning ( $d-1,0)$ and end $(d 26,27)$ of the trial, and on $d 14$. Animal health was assessed daily throughout the course of the study. On d 6, all steers received a booster vaccine against Bovine Viral Diarrhea Virus (BVDV; Bovi-Shield Gold, One Shot, Zoetis). One representative steer per pen was sampled for blood and liver; the same 36 steers were sampled each time. Serum collected on d 1 and 26 as well as liver collected on $d-3$ and 24 was analyzed for $\alpha$-tocopherol (the active form of $\mathrm{VE}$ ) via HPLC. Serum collected on d 6 (prior to vaccination), 14 and 26 was analyzed for BVDV type 1 antibody titers via virus neutralization.

Data were analyzed using Proc Mixed of SAS 9.4 with pen as experimental unit and fixed effects of treatment and block. Contrast statements (linear, quadratic, and cubic) were constructed to determine the effects of increasing supplemental VE. Performance data for one LOW pen were removed based on outlier analysis and performance data for one MED pen were removed due to overall negative ADG by one steer. Initial serum and liver $\alpha$-tocopherol concentration were used as covariates in analysis of final data. Antibody titers from d

Copyright (C) 2021 by the Authors. This is an open access article published under the CC BY-NC license (https://creativecommons.org/licenses/by-nc/4.0/), which allows for non-commercial reuse with proper attribution. 
6 were used as covariates in analysis of d 14 and 26 titers. Antibody titers were log transformed to meet normality assumptions. Morbidity data were analyzed using Proc GLIMMIX of SAS 9.4. Pearson correlations between serum and liver $\alpha$-tocopherol concentrations were determined using Proc CORR of SAS 9.4. Data are reported as least square means $\pm \mathrm{SEM}$. Significance is declared at $P \leq 0.05$ and tendencies from $0.05<P \leq 0.10$.

\section{Results and Discussion}

Serum $\alpha$-tocopherol $<2.0 \mathrm{mg} / \mathrm{L}$ is considered deficient, 2.0 to $3.0 \mathrm{mg} / \mathrm{L}$ is considered marginal, and $>$ $3.0 \mathrm{mg} / \mathrm{L}$ is considered adequate in adult cattle. Based on these values, steers were adequate in $\mathrm{VE}(3.9 \pm 1.0 \mathrm{mg} / \mathrm{L})$ to start the trial regardless of treatment. After $26 \mathrm{~d}$, serum $\alpha$-tocopherol concentrations increased linearly due to supplemental VE (Figure 1A; $P<0.01$ ). Similarly, liver $\alpha$-tocopherol concentrations increased linearly after $24 \mathrm{~d}$ of VE supplementation (Figure 1B; $P<0.01$ ).

Unsupplemented CON steers experienced a decline in VE status and had marginal serum $\alpha$-tocopherol $(2.7 \mathrm{mg} / \mathrm{L})$ by the end of the trial. Therefore, cattle with adequate $\mathrm{VE}$ status entering the feedlot may experience a rapid decline in VE status due to the stress and immune challenges encountered during feedlot receiving. Supplementing VE to steers at the current recommendation for non-stressed cattle (LOW; $11 \mathrm{IU} / \mathrm{lb}$ DM) was enough to prevent a decline in VE status over the 26-d trial. Serum and liver $\alpha$-tocopherol concentrations were positively correlated ( $\mathrm{r}$ $=0.44$ [initial]; $\mathrm{r}=0.69$ [final]; $P=0.01$ ). These data support previous research showing serum and liver to be reliable indicators of VE intake or status. Additionally, these data indicate a liver sample, which is more difficult to collect than a blood sample, is probably not required to assess VE status.

Although changes in VE status due to supplemental VE were observed, initial and final BW were not affected (Table 2; $P \geq 0.75$ ), nor was overall (d 0 to 27$)$ DMI, ADG, or G:F ( $P \geq 0.37)$. Interim feedlot performance was variably affected by supplemental VE throughout the trial. Vitamin E supplementation to newly received calves at doses greater than $400 \mathrm{IU} / \mathrm{steer} / \mathrm{d}$ has been shown to positively impact feedlot performance. However, performance responses to supplemental VE have been variable. It has been established that VE is necessary for optimal immune function and increasing supplemental VE has decreased illness in newly arrived calves. In the current study, it was expected supplemental VE would increase antibody titers in response to a booster vaccine. Regardless of treatment, antibody titers numerically decreased over time, possibly a result of initial antibody titers being elevated from a previous vaccination that occurred at the cow-calf operation (Table 3). There was a linear effect of VE on d 26 (20 d postvaccination) BVDV type 1 antibody titers $(P=0.04)$, where the decrease in antibody titers was least for steers receiving supplemental VE at 1,000 IU/d. Supplemental VE did not affect the percentage of steers treated for respiratory disease ( $P \geq 0.44$; Table 2 ). Because all treatments for respiratory disease occurred prior to $\mathrm{d} 10 \mathrm{of}$ the study, steers may have already been on the verge of illness prior to or only a few days after the start of VE supplementation began. Thus, VE may need to be supplemented for a longer period of time prior to disease outbreak to influence treatment rates. Respiratory treatment percentages by block were $0,2.7$, and $13.6 \%$ for weaned, bawling heavy, and bawling light, respectively, confirming that weaning prior to shipment and body weight are important factors for decreasing disease incidence during the feedlot receiving period.

\section{Acknowledgements}

The authors wish to acknowledge the graduate and undergraduate research assistants of the Hansen Ruminant Nutrition Lab at Iowa State University as well as the Iowa State Beef Nutrition Farm crew. Additional thanks to DSM for partial financial support of this project. 
Table 1. Ingredient composition of common diet fed to steers throughout the trial

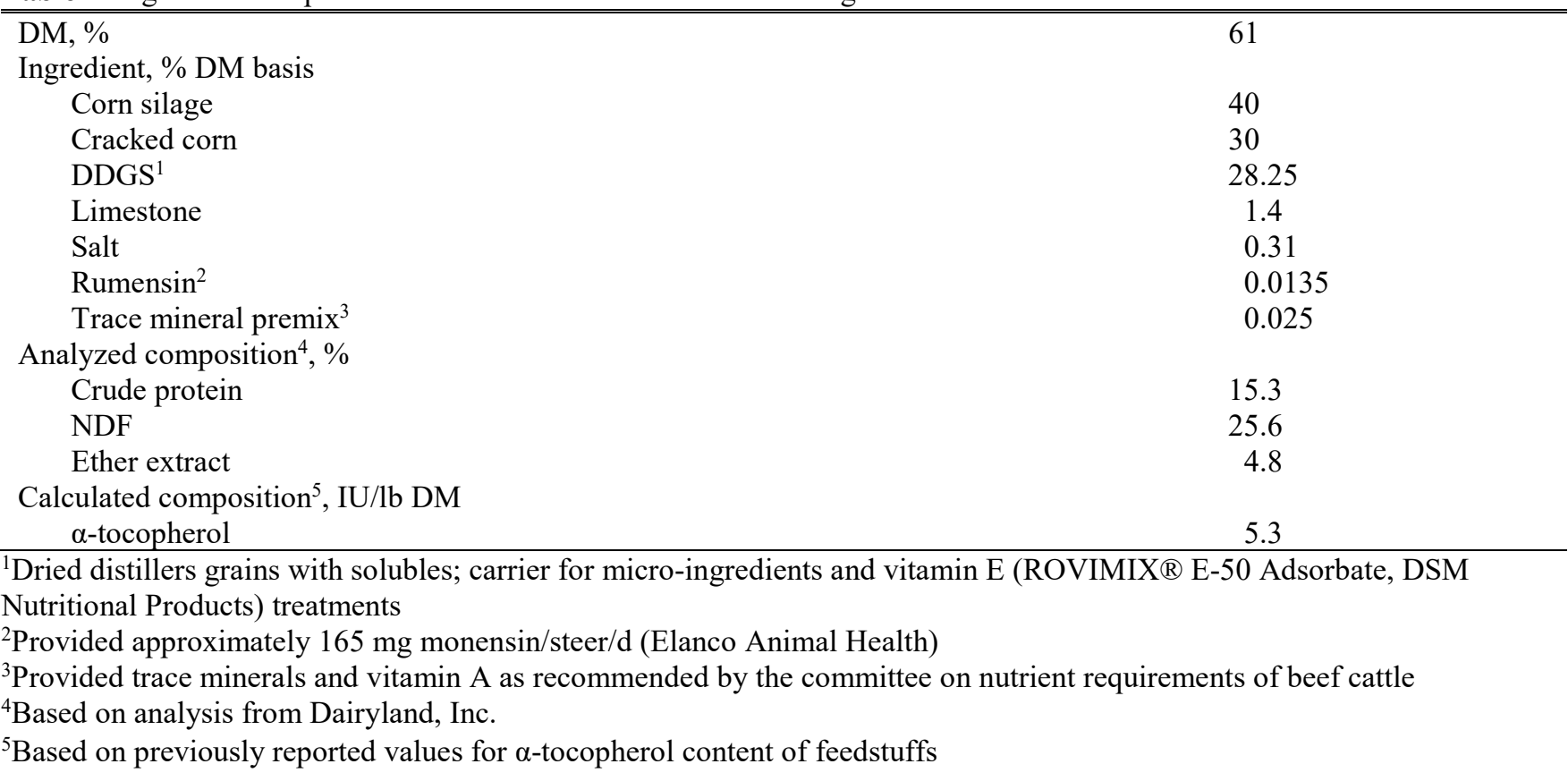

Table 2. Effect of supplemental vitamin E on receiving period performance by beef steers

\begin{tabular}{|c|c|c|c|c|c|c|c|c|}
\hline & \multicolumn{4}{|c|}{ Supplemental VE Treatment ${ }^{1}$} & \multirow[b]{2}{*}{$\mathrm{SEM}^{2}$} & \multicolumn{3}{|c|}{ Contrast $P$-value } \\
\hline & $\begin{array}{c}\text { CON } \\
\mathrm{n}=9 \text { pens }\end{array}$ & $\begin{array}{c}\text { LOW } \\
\mathrm{n}=8 \text { pens }\end{array}$ & $\begin{array}{c}\text { MED } \\
\mathrm{n}=8 \text { pens }\end{array}$ & $\begin{array}{c}\text { HIGH } \\
\mathrm{n}=9 \text { pens }\end{array}$ & & Linear & Quadratic & Cubic \\
\hline VE intake $^{3}, \mathrm{IU} /$ steer/d & 0 & 151 & 484 & 995 & - & - & - & - \\
\hline Initial $(\mathrm{d}-1,0) \mathrm{BW}, \mathrm{lb}$ & 546 & 550 & 540 & 545 & 18.0 & 0.88 & 0.84 & 0.75 \\
\hline Final $(\mathrm{d} 26,27) \mathrm{BW}, \mathrm{lb}$ & 661 & 663 & 665 & 662 & 10.6 & 0.96 & 0.81 & 0.99 \\
\hline \multicolumn{9}{|l|}{ DMI, lb/d } \\
\hline d 0 to 14 & 10.9 & 11.4 & 10.8 & 11.3 & 0.18 & 0.57 & 0.28 & 0.01 \\
\hline d 14 to 27 & 15.9 & 15.4 & 15.7 & 15.7 & 0.19 & 0.98 & 0.48 & 0.10 \\
\hline d 0 to 27 & 13.4 & 13.4 & 13.2 & 13.5 & 0.18 & 0.79 & 0.37 & 0.71 \\
\hline \multicolumn{9}{|l|}{$\mathrm{ADG}, \mathrm{lb} / \mathrm{d}$} \\
\hline d 0 to 14 & 4.24 & 4.04 & 3.99 & 4.24 & 0.122 & 0.70 & 0.08 & 0.65 \\
\hline d 14 to 27 & 4.31 & 4.43 & 4.77 & 4.44 & 0.133 & 0.39 & 0.02 & 0.53 \\
\hline d 0 to 27 & 4.27 & 4.23 & 4.37 & 4.34 & 0.092 & 0.39 & 0.67 & 0.46 \\
\hline \multicolumn{9}{|l|}{ G:F } \\
\hline d 0 to 14 & 0.389 & 0.356 & 0.369 & 0.377 & 0.013 & 0.99 & 0.24 & 0.13 \\
\hline d 14 to 27 & 0.272 & 0.288 & 0.304 & 0.283 & 0.008 & 0.39 & 0.01 & 0.94 \\
\hline d 0 to 27 & 0.319 & 0.316 & 0.330 & 0.322 & 0.007 & 0.54 & 0.38 & 0.38 \\
\hline Treated $^{4}, \%$ & 4.3 & 9.4 & 6.7 & 6.7 & 15.6 & 0.84 & 0.68 & 0.44 \\
\hline
\end{tabular}

${ }^{1} \mathrm{VE}=$ vitamin E (ROVIMIX ${ }^{\circledR}$ E-50 Adsorbate, DSM Nutritional Products); CON = control (no supplemental VE); LOW =

$\mathrm{VE}$ at $11 \mathrm{IU} / \mathrm{lb} \mathrm{DM} ; \mathrm{MED}=\mathrm{VE}$ at $500 \mathrm{IU} /$ steer/d; HIGH $=\mathrm{VE}$ at $1000 \mathrm{IU} / \mathrm{steer} / \mathrm{d}$

${ }^{2}$ Highest SEM of any treatment reported

${ }^{3}$ Back calculated supplemental VE intake based on steer DMI and treatment premix inclusions

${ }^{4}$ Percentage of steers treated once for respiratory illness 
Table 3. Effect of supplemental vitamin E on Bovine Viral Diarrhea Virus type 1 antibody titers of beef steers

\begin{tabular}{|c|c|c|c|c|c|c|c|c|}
\hline & \multicolumn{4}{|c|}{ Supplemental VE Treatment $^{1}$} & \multirow[b]{2}{*}{ SEM } & \multicolumn{3}{|c|}{ Contrast $P$-value } \\
\hline & $\mathrm{CON}$ & LOW & MED & HIGH & & Linear & Quadratic & Cubic \\
\hline Day of sam & & & & & & & & \\
\hline $6(0)$ & 2.3 & 3.0 & 3.6 & 2.4 & - & - & - & - \\
\hline $14(8)$ & 1.7 & 1.7 & 1.4 & 2.1 & 0.24 & 0.32 & 0.17 & 0.47 \\
\hline $26(20)$ & 1.5 & 2.1 & 2.0 & 2.5 & 0.33 & 0.04 & 0.77 & 0.29 \\
\hline
\end{tabular}

${ }^{1} \mathrm{VE}=$ vitamin E (ROVIMIX ${ }^{\circledR}$ E-50 Adsorbate, DSM Nutritional Products); CON = control (no supplemental VE); LOW = $\mathrm{VE}$ at $11 \mathrm{IU} / \mathrm{lb} \mathrm{DM} ; \mathrm{MED}=\mathrm{VE}$ at $500 \mathrm{IU} / \mathrm{steer} / \mathrm{d} ; \mathrm{HIGH}=\mathrm{VE}$ at $1000 \mathrm{IU} / \mathrm{steer} / \mathrm{d}$

${ }^{2}$ Natural log transformed; log transformed means and SEM presented

${ }^{3}$ Blood was collected prior to administration of a booster vaccine (Bovi-Shield Gold, One Shot, Zoetis) on d 6 of the study and antibody titers from d 6 were used as a covariate in analysis of subsequent sampling days; days relative to vaccination are indicated in parentheses
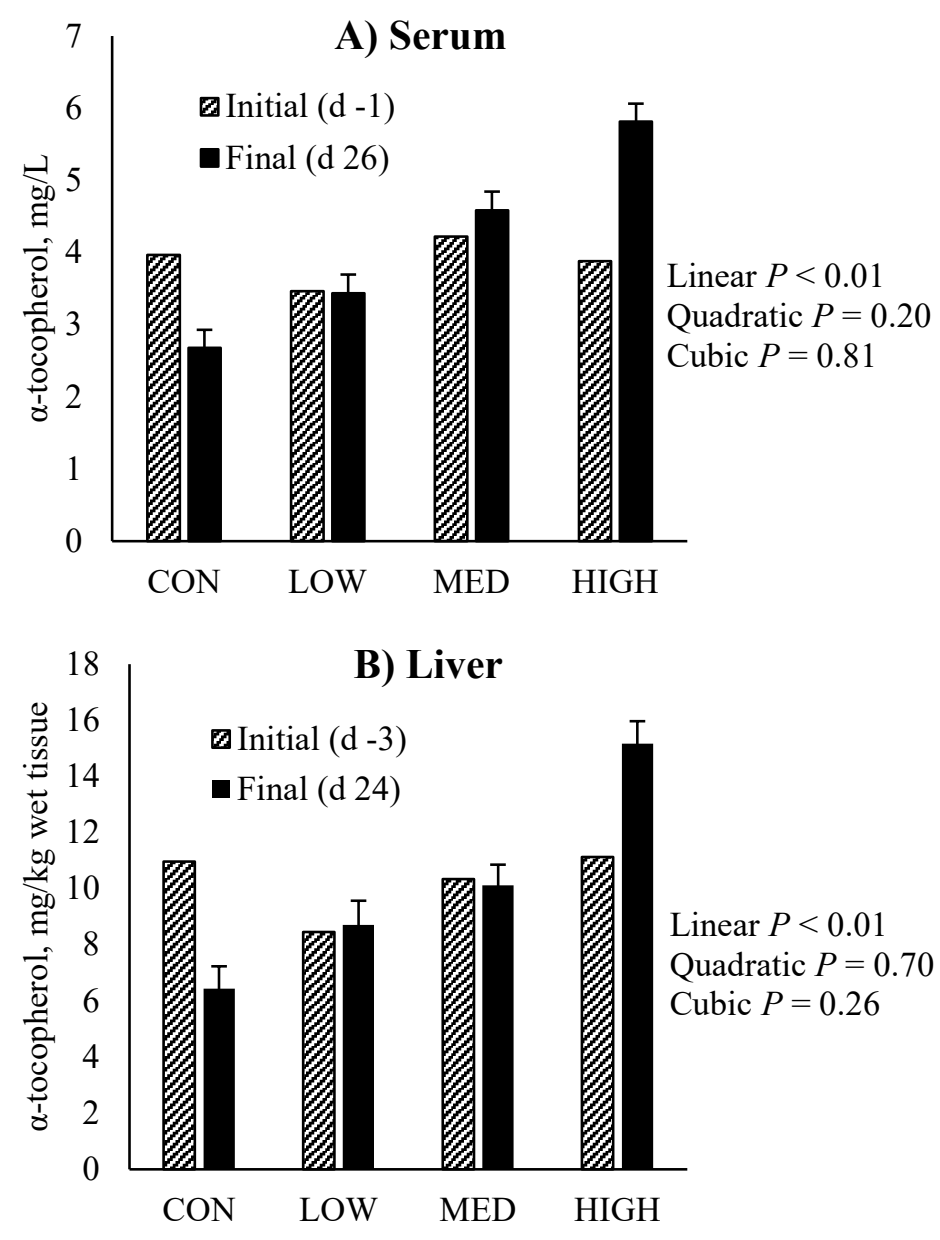

Figure 1. Effect of supplemental vitamin E (VE; ROVIMIX ${ }^{\circledR}$ E-50 Adsorbate, DSM Nutritional Products) on serum (A) and liver (B) $\alpha$-tocopherol and concentrations of beef steers. Initial concentrations were used as a covariate in analysis of final concentrations. Supplemental VE treatments included: CON = control (no supplemental VE), LOW = VE at $11 \mathrm{IU} / \mathrm{lb} \mathrm{DM}$, $\mathrm{MED}=\mathrm{VE}$ at $500 \mathrm{IU} /$ steer/d, and $\mathrm{HIGH}=\mathrm{VE}$ at $1000 \mathrm{IU} /$ steer/d. 